\title{
A Traditional Approach Towards Identification and Evaluation of the Components of Verbal and Nonverbal Communications in the Tea Houses of Tabriz
}

\author{
Gholamreza Azari ${ }^{1}$, Mehran Samadi ${ }^{2}$, Esmaeil Jafari ${ }^{2,}$, \\ ${ }^{1}$ Department of Communication Sciences, Islamic Azad University of Central Tehran, Tehran, Iran \\ ${ }^{2}$ Department of Communication Sciences, Islamic Azad University of Tabriz, Tabriz, Iran
}

Email address:

esmaeiljafaribastan@gmail.com (E. Jafari)

*Corresponding author

\section{To cite this article:}

Gholamreza Azari, Mehran Samadi, Esmaeil Jafari. A Traditional Approach Towards Identification and Evaluation of the Components of Verbal and Nonverbal Communications in the Tea Houses of Tabriz. Humanities and Social Sciences. Vol. 5, No. 4, 2017 , pp. $130-137$. doi: $10.11648 /$ j.hss.20170504.11

Received: April 24, 2017; Accepted: May 8, 2017; Published: June 21, 2017

\begin{abstract}
Communication is one of the main activities of human beings through which they can convey their needs and messages to each other and also understand what others need or want and do. Of course, this is not fulfilled merely through verbal and written activities; but behavioral activities including both verbal and nonverbal elements (vocals), speech tones, and sounds play essential roles. Hence, the main objective of this study is to identify and then evaluate the components of verbal and nonverbal communications in the tea houses (traditional cafés) of Tabriz, a city in northwestern Iran. To achieve this aim, the data collection was conducted through interview and observation. The population of the study included all the tea houses and their customers scattered in Tabriz. Then cluster sampling method was used and all the tea houses were divided into 3 main groups of overcrowded, medium and low-crowded. Accordingly, 4 tea houses were selected from each of these groups and the samples were chosen randomly. Furthermore, this study emphasizes Habermas's theory of the Public Sphere and Albert Mehrabian's verbal and nonverbal communications. The findings suggest that there is no significant difference between verbal and nonverbal communications in the tea houses of Tabriz, though nonverbal communications enjoy relative independence and also act as supplementary to verbal communications. Meanwhile, the results indicate that the functions of tea houses have changed and their role has faded.
\end{abstract}

Keywords: Tea House, Verbal Communication, Nonverbal Communication, Habermas

\section{Introduction and Literature Review}

Tea houses are social places that often don't let strangers to their privacy. Despite their lively appearance, they are calm and impervious. In order to identify the real essence of tea houses, we firstly need to know about their customers and inhabitants. This social institution has changed over time in Iran. Tea houses first emerged as caravansaries in cities or fields alongside the roads. Gradually, as population grew and cities and social businesses developed, caravansaries turned into tea houses associated with various businesses. With the development of folk literature, tea houses changed into places where different stories about human life could be exchanged.
But nowadays, there is not a positive attitude towards these places which are some parts of Iranian folklore heritage. Tea houses first emerged as places where poets, scholars and writers came together namely, they were considered as literary circles. Over time, they changed into hangouts for folklore artists like rhapsodes, storytellers, mimickers, itinerant musicians, painters, puppeteers and traditional comic groups who didn't have any place to present their artistic skills before the tea houses came to existence. So, these artists gradually realized that tea houses, which gathered people from different businesses, are suitable stages for showing their artistic skills. Therefore, they turned into hangouts for different businesses from industry to music. People from every group and business gathered around the 
tea houses and discussed problems about their jobs and businesses for hours. Some people came to find a job and offer a service and some helped others to get their job done. In fact, tea houses belonged to everyone. Apart from their social, cultural and artistic practices, these institutions could have a significant social role in the society and act as resorting places for people seeking help.

Tea houses had also played political and social roles in the society. Before the radio was invented, rhapsodes attended the tea houses to inform people about the latest political and social news. They criticized governments for the imposition of wrong practices and injustice in the society both humorously and seriously. Although the political and cultural roles of tea houses have faded these days and they're rather used as places for spending time, but "the oral history", still, is the most important legacy of a nation. Because communication is one of the main activities of human beings through which they can convey their needs and requests to each other and know what others want and do; and this is not fulfilled only through verbal and written activities. In this regard, behavioral activities including both verbal and nonverbal elements (vocals), speech tones, and sounds play critical roles. Human beings constantly send nonverbal messages in daily. These messages might include blinking, gesturing, moving hands around, and pointing with hand, foot or eye. Such nonverbal messages of human interactions can be more important than what we think. Understanding the audience feedback is the most effective way to persuade the audience for efficacy or reassurance.

In a traditional communication:

1. Communication is often face to face

2. Individual and group personalities, behavioral characteristics and facial expressions have more crucial roles

3. The communicator is visible to everyone

4. Technological tools are not utilized (and if used, they are limited)

5. Simple and understandable words are used

6. People are linked to each other and there's a direct communication between them

7. The benefits of the traditional communication are not tied to the interests of those in power and are free from the shackles of control and can act bluntly and explicitly [6].

Considering what was mentioned, the main objective of this study is to identify and then evaluate the components of verbal and nonverbal communications in the tea houses of Tabriz.

Iran in general, and Azerbaijan region and Tabriz city in particular, are known as the bridge between Asia and Europe which have been under constant attacks by enemies from all directions (Russians from north, Ottomans from west, Mongols of Eastern Asia and even Germans of western Europe). This has caused them to preserve local traditional texture, art and culture, and at the same time adapt those of the other cultures. The linguist and anthropologist, William Orman Beeman (2008) who has lived in Iran for several years, believes that the interpersonal behavior of Iranians possess aesthetic dimensions and has compared it to the art. He proposed that an analogy between Iranians' interpersonal relationships and art is not something irrational. Since succeeding in many affairs depends on the individual's communication skills, so the verbal skills and language usage play a critical role in everyday life.

Habermas, in his theory of "Public Sphere", states that in $17^{\text {th }}$ and $18^{\text {th }}$ centuries such spheres as cafes and cafeterias were used as hangouts for the elite and the enlightened to discuss political and social issues and to exchange ideas, and they had a major role in shaping the public opinion. Newspapers had an ideal and professional function at that period and largely reflected the public opinions in these spheres [5]. Throughout the history, there has been a profound relationship between traditional communications and public sphere in Iran. In this seemingly simple network, all dimensions of society were related to each other as fast as possible, and many of those traditional communication centers were regarded as the sources for thoughts, decisions and main political-social and even economic plans. In other words, the numerous and varied collection of traditional communication centers had been shaping the public opinion of the society.

According to Richmond, human communication is a process through which an individual transfers a concept to another individual's mind via verbal and nonverbal messages. Meanwhile, Miller believes that verbal communication is important because it is one of the effective tools of human being to control and understand his environment; at least for majority of the individuals, being skillful in utilizing communication is one of the best tools for getting the rewards of life and minimizing punishment. Verbal communication is very important because it is one of the primary tools of human beings to affect, control and understand their surroundings.

Due to its different social, cultural and artistic functions in the society and the existence of numerous interactions, all verbal communications are framed as human communication. The relationships between individuals include different concepts and forms. Individuals commute to tea houses for different reasons; they exchange culture or information and also learn. All these events happen through verbal and nonverbal communications. Ray Birdwhistell, a pioneer in the study of nonverbal communications, found that 65 percent of the meaning in a special situation has been transferred through nonverbal and 35 percent through verbal communications. Albert Mehrabian (1967) analyzed the exchange of messages in an interpersonal communication and found that 93 percent of the messages were communicated through nonverbal and only 7 percent through verbal. According to his findings, of 93 percent nonverbal communication 38 percent had phonetic signs (Trans verbal) and 55 percent had facial signs [6]. Verbal communication is important because it is one of the useful tools of human being to control and understand his environment and its effects, and for majority of the individuals, being skillful in utilizing 
communication is one of the best tools for getting the rewards of life and minimizing punishment. Also, a specific language can be achieved through the study of nonverbal communication. These languages have, at least, one thing in common and that is signs or guidelines which can be used in interpretation of human behavior. Sign means to notify, imply or inform. For instance, when you're told that you haven't responded to a sign, it means that you didn't get the point. Individuals provide us with many clues through their nonverbal messages or show signs about their excitements, desires, intentions, personality and even social status [1].

Ulusoy (2011) conducted a study on the culture of coffee and tea houses among the people of Turkey. In this research, the verbal and social culture of coffee and tea houses were studied using interviews and questionnaires. According to the descriptive findings, the Turkish coffee has not lost its popularity among the Turks despite the widespread publicity of foreign brands, and serving Turkish coffee in formal ceremonies is regarded as a social prestige. Tasseography is very common in this country as 58 percent of respondents told that one of the reasons they drink coffee is that they're curious about knowing what lies ahead. In this study, it was released that 76.4 percent of spectators attended the sport events along with their friends for entertainment and to establish social relationships, and 23.6 percent for relaxation and refreshment. Harun Ürer (2010) studied the visual culture and architecture of Ottoman tea houses using a documentary method. In the middle of $16^{\text {th }}$ century (15661574 A.D.), Ottoman tea houses were closed with the fatwa of Sheikh al Islam Abu-Said claiming that coffee is harmful for humans. After the reopening of tea houses, they were closed again in 1595 and 1603 , but since 1607, tea houses with their spectacular design and charming beauty continue to serve the local people in addition to foreign tourists. Different types of Ottoman tea houses include: business, coastal, street and local tea houses. The social status of customers represented the importance and grandeur of a tea house. Luxurious tea houses were furnished with rugs and backrests instead of stool and bench which were often found in coastal and cheap tea houses. In recent years, Turkish tea houses have used the ottoman architectural style to attract more tourists.

Heidarkhani and Mowlana (2011) studied the social function of tea houses with a report on tea houses of Tabriz. After taking photos and interviewing with owners of some old tea houses of Tabriz and Behrouz Khamachi (a local historian), they presented their study as a pictorial report. The results of their assessment of the tea houses of Tabriz showed that these tea houses have different social and cultural status, and doing charity works is among the legacies the tea houses inherited from their ancestors. Rhapsodies and hymn ceremonies are held in some tea houses, but the police have prohibited live traditional music like Ashiqs in tea houses. Another problem is that health office prevents the tea houses from preserving their traditional architecture, old decoration and walls.

Amian (1993) studied the social role of Iranian tea houses by overviewing tea houses of Khoy. Amian reported that there were 125 independent, 25 hotel-affiliated and 20 unlicensed tea houses in Khoy. The survey reported that tea houses had about 50 to 500 customers every day. Out of 150 tea houses, 91 were situated in downtown, 23 in the midtown and 56 in the suburbs. Downtown and suburb tea houses had higher quality and better services.

With regard to the findings of the study, nonverbal signs play a very important role in interpersonal communication. One of the institutions interwoven with verbal and nonverbal communication is tea house which can present culture and social relations to researchers and tourists. Coffee houses were the first social institutions in Iran [3]. Tea houses, like other institutions, have changed over time and have lost their previous functions. Tea houses have different forms in different cities but the tea houses of Tabriz are somehow unique. They are divided into two groups: public and business. Tea houses are centers and part of the society that often don't let strangers to their privacy. Despite their lively appearance, they are calm and impervious and one must know their inhabitants in order to know their real function.

Therefore, tea houses are important because they act as a cultural institution. Moreover, nowadays young people go to tea houses more than ever, so the roles of verbal and nonverbal communications common in these places are particularly important. But, this study shows that the analysis of tea houses as a cultural legacy has been neglected. In addition, it proves that verbal and nonverbal behaviors of human beings have not been taken seriously. So, the lack of sufficient studies on the subject under discussion is apparent. It seems that a careful and regular planning based on present needs of the society and tea house-goers and restoring the lost grandeur of tea houses need the study and understanding of common communication culture among them. Considering the fact that one of the researchers of this study has been a tea house-goer for years and is objectively familiar with the environment, different functions and communications common in tea houses, he suggested studying the components of verbal and nonverbal communications in the tea houses of Tabriz.

\section{Methodology}

The aim of this study is to introduce the tea houses of Tabriz based on verbal and nonverbal communications. The combined method of interviewing and observation (qualitative-quantitative) was used in the study. The population of licensed tea houses in Tabriz was 323 in this study. With regard to the fact that tea houses in Tabriz are used as hangouts by specific classes of people and have specific functions, and according to the recommendations and comments of the study supervisors, the whole population was divided into 3 main groups: overcrowded, medium and low-crowded. Then, 4 tea houses were selected randomly from every group. The selected tea houses included:

a. Overcrowded: Bastan, Safa, Salar, Boland Nazar

b. Medium: Ashiqlar, Khorshid, Dastan, Sazandalar 
c. Low-crowded: Heydar, Qushbazlar, Shotorban, Lotfi

122 questionnaires were filled out according to the number of customers of sample tea houses and the study was conducted in 12 tea houses of Tabriz. The time spent on this study was:
a. All interviews: 20 days
b. Every interview: 45 minutes to 1 hour
c. Observation: 10 days
d. Photography: 4 days

\section{Results}

According to the findings of the present study the age average of the respondents was 32 years old; the age range was 19 to 81 years old; 61.5 percent of the customers had university degrees; 3.3 percent had finished secondary school and 6.6 percent had an elementary school degree or were illiterate.

According to the observations of the researchers, the tea houses of Tabriz (called cafés in local language) have some specific characteristics which are different from their counterparts in other cities. Most of these tea houses are business related; i.e. people involved in a specific business go there and communicate with each other. These tea houses are the home address of many of the business workers. Overall, it can be said that tea houses play a mixed role of a dinning place, job placement agency, relaxation and entertainment for workers and craftsmen, or in modern language, tea houses are like traditional clubs.

Also, in the study of the verbal behaviors with the use of interview, it was observed that 32.8 percent of the respondents try to speak slowly and fluently or change their tone to be understood clearly by the addressee. 39.3 percent know that some words can evoke several different meanings in the mind of the addressee and remind him of various subjects and 29.5 percent attempt to focus their attention on the subject they are talking about. 32.8 percent use slangs, proverbs and poems to make their speech pleasant. 32 percent try to use specialized vocabulary only if the addressee is familiar with them. 33.6 percent speak in details to get their message across to the addressee. 36.1 percent try to communicate through methods they deem suitable, and 31.1 percent use a large number of examples and specific cases while speaking.

In terms of nonverbal communications, such elements as entrance facade, interior decoration, and certain customs and customers' entertainment were considered in this study. These features were analyzed as follows:

Bastan: Founded in 1946, this tea house is a 70 -year-old hangout for the young and old. It is among the few tea houses allowing ladies in; and part of the tea house is separated by a curtain for women. It used to be a hangout for the elites such as Gholām-Hossein Sā'edi (well-known national writer) and Gholam Yahya (high-rank politician), and currently serves artists, workers, retired military personnel, teachers, businessmen, architects, university students, carpet weavers, domestic and foreign tourists. The tea house's entrance is a place for getting information and paying the bills, and tables are arranged so that customers sit facing each other.

The principles of masculinity and machismo still exist in this tea house. Whenever a needy person (specially a woman) comes to the tea house, a young man takes a plate and walks around the tea house to collect money for him/her. When a vendor comes in, the customers usually help him/her by buying things from them. There are some specific seats belonging to some specific people in the tea house. A stranger sitting on one of these seats stands up as the "owner" enters the tea house. Moreover, different groups have their own specific seats. The seats in the left side of the tea house's entrance are for building workers. The retired sit in the right side and the educated in the middle seats of the tea house. It is also among the few tea houses serving food.

Ashiqlar (meaning: traditional Azeri singers): This is a business tea house and has specific customers. It has some commodes for keeping Ashiqs' musical instruments in. Tables are arranged so that customers sit facing each other. There is a place for keeping Ashiqs' business cards, so they can be easily contacted in the case of a wedding ceremony. The tea house's owner gets a commission on every customer an Ashiq finds in the tea house. In this tea house, Ashiqs play music and sing songs as a way of communicating with each other. There are no strangers among the customers of the tea house, except for those who have come to the tea house to reserve or invite an Ashiq to their wedding ceremonies.

Qushbazlar (literally: birdmen): It's a business tea house letting no strangers in unless one of the customers brings his friend as a guest or a new customer. It has a low social level and is the hangout for pigeon lovers. Pigeons of Tabriz are a breed of carrier and tumbler pigeons; the popular pigeons rolling over backward while flying (also called Mayallaghi). Even, there are some pigeons more expensive than a car. In this tea house, the tables are arranged so that customers sit facing each other. It is one of the busiest tea houses in Tabriz. The tea house owner gets a commission on every pigeon sold. The owners of expensive pigeons are the most respected ones in this tea house.

Sazandalar (literally: musicians): It was established about 20 years ago and is closed on holidays. Often, ordinary people come here to relax and listen to live music. It has desks made of aluminum. All of its interior walls are furnished with mirrors and tables are arranged beside the walls. The interior decoration is beautiful. There is a "scene"like place at the entrance of the tea house for musicians and singers to perform. There's a small pond in the middle of the tea house. If an elder enters the tea house, the other customers say "Ya Allah" with a loud voice to address him. Every customer has a specific seat and table. The instruments for sale are kept in the drawers of the desk. Buying and selling musical instruments happen in specific predefined times. Live music is also played on specific days of the year.

Khan Salar: This tea house is 40 years old. It has various customers most of whom are close friends with each other. All the interior walls are furnished with mirrors and tables are arranged beside the walls. There are many flowers in the 
middle of the tea house. Tableaus of Tabriz hung on the walls. Smokers and non-smokers have their own seats in this tea house, and a cigarette smoker is not allowed to sit next to a person who smokes hookah.

Lotfi: This tea house is 60 years old. It has been the hangout for such well-known national writers as Samad Behrangi, Jalal Al Ahmad and Behrouz Dehghani. Currently, businessmen and educated people are among the customers of this tea house. Natural flower pots are used for decoration and pictures of famous people and old hookahs are hung on the walls. Tables are arranged beside the walls, also there are some seats and tables in the middle of the tea house. Reading books is more popular in this tea house compared with other ones. Every person has a specific seat and smokers and nonsmokers have their specific places. In ceremonies, customers are served with confections and in such religious periods as Muharram and Safar, tea and hookah are served at no cost. If the needy enter the tea house in the day of Tasu'a (the ninth day of Muharram), they would get money from the customers as charity.

Boland Nazar: This tea house is so old and dates back to a century ago. It's also one of the most interesting places of Tabriz. Images of Shiite Imams, local and national champions and the late owner of the tea house are hung on the walls. There are other desks like the ones in the stores that sellers keep their stuff in. Also, birds like canaries and old things like hookah accessories (cups) are part of the decoration of this tea house. With its traditional theme and old paintings hung on the walls, the tea house welcomes tourists from different countries including Serbia, Azerbaijan, Germany and Uzbekistan. The interior walls are furnished with mirrors and seats and tables are arranged in the middle of the tea house. Different customers have their specific places in this tea house; a cigarette smoker, for example, is not allowed to sit beside a person who smokes hookah. Young people sit away from the elderly. Buying and selling goods like rings, coins, old paper money, hookah inhalers (Amjak), old watches, old hookahs, prayer beads etc., are done forenoon in this tea house. Every seller has a personal table for which he pays a monthly rent. Sometimes, the tea house owner gets a commission on selling the stuff. The tea house is divided into two parts of left and right, with tables arranged in the middle. Buying and selling goods are done in the right side of the tea house in the morning, and the tables on left side are for those who want to smoke hookah. Smoking hookah is permitted in all the tables in the afternoon. Of course, cigarette smokers have their specific tables so they don't bother hookah smokers. In Muharram and Safar, some black clothes are hung on the walls as the symbol of mourning for Shiite Imams. Antique artifacts are hung on the walls of the tea house and everyone has a specific place to smoke. Young people come to this tea house after 4 o'clock in the afternoon just for entertainment.

Safa: This tea house is about 70 years old. It is one of the tea houses that has gathered most of city actors and TV artists together. Safa is the only tea house in Tabriz which has both a roofed hall and an open space outside. All the interior walls are furnished with mirrors and the tables are arranged close to the walls. The yard is full of garden flowers, bushes and trees and there is a big pond in the middle of the yard too. The tables in the yard have been covered with a canopy, so the customers don't get wet at rainy or snowy days. Its outdoor part is the reason for many people to be there. Since there are many beautiful trees and flowers in the yard, the tea house looks quite pleasant. The place of the tea house is above the street level which provides special view for the customers, and many people also go there because of its ease of access. Everyone has special seat for himself and groups gather around their specific tables. This tea house, like Bastan, serves food in addition to tea and hookah.

Shotorban (known as: Esrafil): This tea house is one of the oldest ones in Tabriz but its exact date of establishment is not clear. The traditional environment and texture of this place attract many tourists. The hearth (a place for burning hookah's charcoal) is located at the entrance of the tea house and Charlie Chaplin's photo is painted on a wall. A portrait is also painted with the smoke of charcoal. Old things are at the left side of the tea house. All the interior walls are furnished with mirrors and tables are arranged next to the walls. There are also some vases, and antiques like a small box and samovar. Such other decorations as the paintings of the artists of this tea house are seen on the walls. Tea is served in small cups and when a customer drinks it all, he can pour tea from the pot (the empty cups remain on the table and are not collected). Everyone has a special seat, e.g., photographers and artists gather around their specific tables. This tea house welcomes tourists. The way the tea house owner behaves towards his customers implies whether the newcomers can come again or not.

Khorshid (Turkish name: Gunash): It was established in 1980. Few strangers come to this tea house and the customers usually don't trust in strangers. It has its own permanent customers. A large poster of Tractor Sazi F. C. (popular team of the city and symbol of Azeri ethnicity) is hung on the entrance hall. A large banner at one side of the tea house reads the religious verse "اللهم عجل لوليك الفرج". There some signs saying: use of laptop and playing loud music by cellphone is not permitted. Artificial vases are used as decoration. All the interior walls are furnished with mirrors and tables are arranged beside the walls. Benefaction is common in this tea house at specific times of the year. People have their special seats, for example there are seats and tables at the entrance of the tea house for the deaf. Poets and educated people have their own tables. The retired businessmen and teachers have their special political views. Some people bet on sporting events. There is also a very important rule in this tea house: lightening a cigarette with the charcoal of a hookah is regarded as an insult and everyone should consider it. This tea house has an unofficial timing: the elderly and retired people go to the tea house in the morning and young people in the afternoon. Most of the customers of this tea house are educated people.

Dastan: Founded in 2013, this place is a newly established tea house in the city. There is an aquarium in this tea house 
and people sit facing each other. Many pictures of city champions and calligraphies of artists are hung on the walls of the tea house. Old and antique things are seen in the tea house too. There are many religious texts, photos and flags on the walls. There is also a "kindness wall" system in this tea house, and a note on the wall reads: 3 teas on the wall. If a needy customer doesn't have money to pay, the cost of his service is paid by others through paying the price and sticking the bill to wall. Customers can also pay for the needy in advance, attach the bills on the wall and be part of this charity work. This tea house provides free WIFI for its customers. Some customers read books or newspapers. Different types of flavored tea such as green tea, sour tea, cinnamon tea, bitter orange tea are served in this tea house. The meals including breakfast, lunch and evening meal are served in this tea house (Baklava is also served as a confection). Meals served for breakfast: omelet and fried eggs. Meals served for lunch: omelet, fried eggs, Kebab, and boiled lentil. Evening meals are the same as the lunch meals. Only cigarette is smoked and there's no hookah in this tea house.

Heydar: This tea house is 30 years old. Tables are arranged beside the walls and the walls are decorated with mirrors and tiles and there is a pond in the middle of the tea house. There are photos of Azerbaijan region and its great heroes. Natural pots can be seen in the tea house. If an elder or a well-known person enters the tea house, other customers say "Ya Allah" loudly to welcome him. Financial problems of the families in the neighborhood are solved by the help of customers and needy people get help as well. Majority of the customers are: carpet weavers, dyers, carpet framers, carpet designers and buyers of carpets and rugs.

\section{Discussion}

Tabriz has a special grandeur because of its role as the crossroad of civilizations and intersection of cultures, its mixed inhabitants of Assyrians, Caucasian immigrants and local people, and a medley of architecture. The tea houses of Tabriz have special characteristics which differentiate them from their counterparts in other cities. Majority of the tea houses are places for gathering and communicating of workers of a specific business. Use of mirrors and tiled walls are the formal decorations of the tea houses in this city. The availability of specific seats for different individuals and groups is regarded as an informal rule in the realm of nonverbal communications. Many of the tea houses are situated in downtown and serve their permanent customers well. But, in some tea houses, strangers and even guests are not welcomed. Sometimes, the customers behave cautiously and conservatively and the new person is hardly capable of communicating with them because the old costumers are reluctant to accept new people in their hangout. But, in some tea houses, especially the old ones, the customers care about the new people and even welcome them. In terms of verbal communication, every tea house has its specific language, tone and environment; but in terms of nonverbal communication, there's no significant difference in communication among individuals and understanding the meaning of symbols and signs. But in terms of environmental nonverbal communications (decorations, ornaments, special customs), every tea house has a specific strategy appropriate for its customers. Most of the times, it can be realized from a tea house's name and title that what type of people are the customers of that tea house and what reaction a person would face in the case of breaking the privacy and entering the tea house. Due to the mixed nature of the customers of the tea houses, these people can be regarded as the presenters and extenders of national and local culture against the foreign attacking cultures. The multiplicity of businesses and professions is one of the reasons of the high number of tea houses. In the mid-60s, many of the tea houses of Tabriz were the hangouts for young intellectuals of Tabriz.

According to the communication theories of George Herbert Mead and Charles Cooley regarding the symbolic interaction theory, communication has expressive and declarative effects. The interactive communication between human beings is about the use of symbols with same meaning and communication is not limited to the use of language; and special language is determined through body gestures against the language signs. Also, Mohsenian believes that the difference between verbal language and nonverbal language is not as easy as the comparison between actions and speech, for example, speech is mixed with nonverbal elements such as tone, silences between the sentences and etc. Richmond, in his communicative theory, discusses which of verbal messages or nonverbal messages are superior; and he concludes that this is something dependent on the situation. Providing a valid generalization about the relative importance of verbal and nonverbal communication is not possible in all situations.

According to Habermas' Public Sphere, such public spheres as tea houses and cafeterias, in the $17^{\text {th }}$ and 18 centuries, were used as hangouts for the elite and the enlightened to discuss political and social issues and to exchange ideas. These places had a major role in shaping the public opinion because newspapers had an ideal and professional time at that period. In Habermas' view, the life world is a source of interpretative patterns that is culturally transferable and linguistically organized. The world is a smaller level where the agents come to an understanding on various issues, in addition to communicating with each other. Studying the history of tea houses, it is realized that these places in Iran have the same function as mentioned in Habermas' theory. Up to the several last decades, the tea houses were centers for publication and distribution of traditional culture and literary and artistic achievements of our ancestors, and they had an important duty and role in ordering of social relations and beliefs and the survival of the values of Islamic-Iranian culture among different groups and classes of people, specially the urban communities. Tea houses were places where people had the chance to discuss their business problems and resolve issues related to family and community. In such recent periods as the Constitutional 
Revolution and the Islamic Revolution, tea houses had a visible and active role as the center of political activities and cultural transfers. But nowadays, verbal and common traditional communications have almost been lost and new communication methods have taken their place. Wi-Fi, smart phones and TV have replaced rhapsodes, epic readers and cultural and political discussions. Verbal and nonverbal communications in the tea houses have taken on a new form. Political and cultural issues have been replaced by economic issues. Some tea houses have changed to a place for finding job for the jobless. It's observed that the public domain has developed through expanding economy. This allows citizens, property owners, merchants, artisans and other members of the community to be actively involved in the running of society, and also to be able to openly discuss various topics and have dialogue with each other.

Habermas argues that the rationality of the public sphere was eroded by some forces that had motivated its development. In his view, the instability of market economy increased the state's power to stabilize economy. As a result, with the development of bureaucracy in all dimensions of social life, public sphere was shrunk. The use of technical means through technology and administrative processes (executive) replaced public debate and arguments. With the expansion of capitalism and the state bureaucracy, the freedom of individuals declined and this led the government gain control over all aspects of people's lives. This is also true in case of tea houses. Today, government regulations are dominant in the tea houses of Tabriz. According to the regulations, applying traditional architecture in the building of a tea house is prohibited, and these places have to conform to specific regulations for the decoration of tea houses to provide services to customers.

\section{Conclusion}

In addition, entertainment is mainly limited to smoking hookah among the elderly and playing with smartphones among the young people. Even, mind games like backgammon and chess are not allowed in the tea houses. The findings of this study are in correlation with those of Albert Mehrabian. He analyzed the messages sent in an interpersonal relationship regarding the verbal and nonverbal communications and found that only 7 percent of the meaning is sent to the addressee through verbal messages. The remaining 93 percent of the message which is sent via nonverbal communication can be divided as: 38 percent had phonetic signs and 55 percent had gesture signs. Although the findings of different studies vary with each other, but it can be concluded that "nonverbal signs" are very important in interpersonal communications and in many cases have a vital role in transferring meaning from one person to another. Consequently, it seems that the phrase "how you say it is more important than what you say" has been rather true. Nonverbal communication does not occur in a vacuum. Nonverbal communication often happens along with verbal communication. Furthermore, although single nonverbal behaviors send independent messages, but usually these messages are interpreted as a message system. Sometimes, we understand the most part of verbal messages and sometimes get the meaning through the joint effect of verbal and nonverbal messages. The findings of the present study indicate the same problem. The similarity between verbal and nonverbal communications in the tea houses of Tabriz indicates that verbal and nonverbal communications are in line with each other and no clear boundaries can be set between them.

According to the findings of the study, it is suggested that:

a. With regard to the fact that the functions of tea houses have changed and these places have turned mainly into entertainment places, it is suggested that facilities for spending healthy leisure time be provided in the tea houses.

b. With regard to the loss of customers in the tea houses and the importance of their decoration and architecture design, for restoring their prosperity and grandeur and attracting more tourists, it is suggested that tea house owners change and rebuild their tea houses and apply a more attractive design and integrate traditional and modern architectures.

c. With regard to the fact that social view is not so optimistic about the tea houses, and people don't go to the tea houses for this reason - though tea houses are still regarded as social and relational centers- it is suggested that specific regulations be devised by tea house owners. If the customers do not conform to the regulations, the owners can prevent them from entering the tea house.

\section{References}

[1] Azari, G. (2006). An introduction to the principles of human communication. Tehran: Education Department of IRIB.

[2] Bitooshi, R. (2015). Evaluating the Role of Human Communication Skill (verbal -non-verbal) of the Staff of Refah-e-Kargaran Bank on Customer Satisfaction. An MA Thesis: Islamic Azad University, Central Branch of Tehran.

[3] Blookbashi, A. (2013). Tea houses in Iran. Tehran: Office of Cultural Researches, $1^{\text {st }}$ edition.

[4] Dadgaran, S. M. (2014). The principles of social communication. Tehran: Firouzeh Publications.

[5] Forghani, M. (2004). An Introduction to Human Communications in Iran. Tehran: Publications of Media Research Center, $1^{\text {st }}$ edition.

[6] Farhangi, A. (2009). Basics of human communication. Tehran: Publications of Rasa Cultural Institute, $14^{\text {th }}$ edition.

[7] Ghasemi, N. (2010). Overviewing the role of traditional communication in the modern world. Kheyme: V46; 5207.

[8] Mirhosseini, A. \& Nourbakhsh, M. (2006). Theories of Communications. Tehran: Jungle Publications, $1^{\text {st }}$ edition.

[9] Moghadam Kia, R. (2008). Language, Status and Power in Iran. Tehran: Ney Publications, $2^{\text {nd }}$ edition. 
[10] Mohsenirad, M. (2006). Communications. Tehran: Soroosh Publications, $6^{\text {th }}$ edition.

[11] Motakefi, F. \& Alaei Cherehbarhagh, A. (2015). Once upon a time in tea houses. Tehran: Jahan Jam-e-Jam Publications, $1^{\text {st }}$ edition.

[12] Mousavi, F. (2009). Nonverbal behavior in interpersonal relations. Tehran: Danesh Publications, $1^{\text {st }}$ edition.

[13] Salasi, M. (2010). Sociological theory in the contemporary era. Tehran: Elmi Publications.
[14] Sarookhani, B. (1997). Sociology of Communication. Tehran: Ettelaat Publications, $2^{\text {nd }}$ edition.

[15] Ulusoy, K. (2011). Turk toplum hayatinda yaşatilan kahve ve kahvehane kulturu (bir s .lu kultur ve sosyal cevre eğitimi calişmasi). millî folklor, 2011, y>l 23, say> 89: 159-169.

[16] Ürer, H. (2010). Osmanli'da kahve/kahvehane kültürü ve salihli'den bir kahvehane örneği "himaye-i etfal. sanat tarihi dergisi. sayı/number xix/2. ekim/ october 2010, 1-26.

[17] Zakavati Gharagozlu, A. Verbal Communication. Tehran: Soroosh Publications, $3^{\text {rd }}$ edition. 